\title{
Improvements on Near Real Time Detection of Volcanic Ash Emissions for Emergency Monitoring with Limited Satellite Bands
}

\author{
Torge Steensen ${ }^{1 *}$, Peter Webley ${ }^{2}$, Jon Dehn ${ }^{2}$ \\ 1 Leibniz Universität Hannover, Germany, 2 University of \\ Alaska Fairbanks, USA \\ *steensen@ipi.uni-hannover.de
}

\begin{abstract}
Quantifying volcanic ash emissions syn-eruptively is an important task for the global aviation community. However, due to the near real time nature of volcano monitoring, many parameters important for accurate ash mass estimates cannot be obtained easily. Even when using the best possible estimates of those parameters, uncertainties associated with the ash masses remain high, especially if the satellite data is only available in the traditional 10.8 and $12.0 \mu \mathrm{m}$ bands. To counteract this limitation, we developed a quantitative comparison between the ash extents in satellite and model data. The focus is the manual cloud edge definition based on the available satellite reverse absorption (RA) data as well as other knowledge like pilot reports or ground-based observations followed by an application of the Volcanic Ash Retrieval on the defined subset with an $R A$ threshold of $0 \mathrm{~K}$. This manual aspect, although subjective to the experience of the observer, can show a significant improvement as it provides the ability to highlight ash that otherwise would be obscured by meteorological clouds or, by passing over different surfaces with unaccounted temperatures, might be lost entirely and thus remains undetectable for an automated satellite approach. We show comparisons to Volcanic Ash Transport and Dispersion models and outline a quantitative match as well as percentages of overestimates based on satellite or dispersion model data which can be converted into a level of reliability for near real time volcano monitoring.
\end{abstract}

\section{INTRODUCTION}

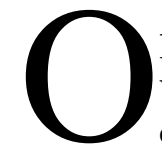

perational monitoring of erupting volcanoes and their ash emissions is crucial for aviation safety [Prata, 1989]. Space observations traditionally use satellite bands spectrally located around 10.8 and $12.0 \mu \mathrm{m}$ as these have been found to have the ability to distinguish volcanic ash from meteorological clouds based on the reverse absorption (RA) feature discussed in Prata (1989).
Traditionally, this method has a threshold of 0 $\mathrm{K}$ which is often reduced to a negative value to avoid false alarms [see Steensen et al, 2013]. A quantitative analysis of ash emissions detected with the RA method, the Volcanic Ash Retrieval (VAR), has been developed by Wen and Rose [1994] and applied to different case studies around the world [e.g. Rose et al., 1995; Gu et al., 2005]. VAR uses the RA maps as base to estimate the ash masses. Important input parameters are surface and ash temperatures. In 
ANNALS OF GEOPHYSICS, XXI, 1, 2015

addition, different Volcanic Ash Transport and Dispersion (VATD) models have been developed and are used globally to track and predict ash movement [e.g. Puff (Tanaka, 1991); NAME ('Nucelar Accident ModEl'; Ryall and Maryon, 1998) and HYSPLIT ('HYbrid Single-Particle Lagrangian Integrated Trajectory; Draxler and Hess, 1997)]. Nonetheless, the accuracy of satellite analyses and VATD predictions depends on their respective input parameters.

In addition, ideal satellite observations are limited to clear-sky conditions as meteorological clouds under- or overlying the ash will hamper the measurements by altering the defacto 'surface' temperature and by shielding the ash from space-borne detection [Wen and Rose, 1994]. More sophisticated approaches exist but require more spectral bands which are not present on all satellites yet (e.g. Pavolonis, 2010).

We developed a new approach combining the advantages of RA-based retrievals and model calculations while acknowledging their respective uncertainties. This also includes a non-automated step in which the user can alter the auto-determined ash extent, determined by the RA approach with the $0 \mathrm{~K}$ threshold, based on additional information like pilot reports or ground-based data sets, which are not recognized in current automated analyses but can provide valuable information regarding the extent of the volcanic ash.

Our case study is the eruption of Kasatochi, a volcano in the central Aleutian Islands of Alaska (Fig. 1A). It erupted violently in August 2008 for the first time in recorded history and emitted ash in three different events. The ash reached heights of $18 \mathrm{~km}$ above sea level and travelled eastwards across the North Pacific Ocean [Waythomas et al. 2010].

This ash cloud was observed with data from the Geostationary Operational Environmental
Satellite (GOES) and modelled with Puff. The parameters we chose for the Puff run are listed in Table 1. As time frame, we chose the initial eruption sequence of the three main events and ignored the following continuous phase as ash heights and the durations for specific heights, essential parameters for VATD runs, have not been recorded.

\section{METHODS}

The Critical Success Index (CSI) is a quantitative measurement tool developed by Stunder et al. [2007] to evaluate the degree of overlap between the volcanic ash extents derived from satellite data and predicted in VATD model data. It is defined as:

$$
\mathrm{CSI}=\mathrm{O} /(\mathrm{S}+\mathrm{O}+\mathrm{M})
$$

where ' $S$ ' and ' $M$ ' are the ash extents only determined in the satellite and modelled data, respectively, and ' $\mathrm{O}$ ' is the overlap between both data sets. In the ideal case, the CSI equals ' 1 ', i.e. a $100 \%$ overlap between both ash extents is shown.

Originally, the CSI value has been developed to evaluate the performance of the HYSPLIT VATD model against satellite data. In order to expand this to compare modelled and observed data sets against each other, without assuming either to be perfectly accurate, we added two further values, the satellite excess (SE) and the model excess (ME) which are defined, analogously to the CSI, as follows:

$$
\begin{array}{r}
S E=\mathrm{S} /(\mathrm{S}+\mathrm{O}+\mathrm{M}) \\
M E=M /(S+O+M) .
\end{array}
$$

Note that the observed data set $(\mathrm{S}+\mathrm{O})$ comprises the satellite data as used by Stunder et al. [2007] and additional data like pilot reports, ground measurements and in-situ sampling. While such sources are scarce in a near real time setting, they will become important in ret- 
roactive analyses using this method.

We use the spatial extent of the Puff calculations as input for our analysis. In addition, we apply the RA method to each satellite image to outline the theoretical ash extent with a $0 \mathrm{~K}$ threshold in the GOES data. This raw outline is later manually modified to reflect information from other data sources.

After obtaining the two extents separately, we can compare them quantitatively by calculating the overlap as well as the respective excess values defined in (2) and (3). The ratio between the three values will change over the course of the eruption, which allows us to draw conclusions about the accuracy of the input data sets and, in turn, their input parameters.

The higher the CSI will be, the more reliable the forecasted ash movement is. If the SE is relatively large, the satellite images with external information show ash where the model doesn't predict it. This can be due to erroneous input parameters for the model data which directly affect the calculated ash extent (e.g. chosen wind pattern or its resolution, height of the ash, etc.). Similarly, a high ME value stands for misrepresentations of the ash in satellite and other data sets. In this case, the VATD model predicts ash but the satellite products as well as other sources can't confirm it. Such errors can be caused by meteorological clouds blocking the ash from being detected or ash concentrations dropping below the detection limit.

Due to this behaviour, it is possible to draw conclusions about the stage of the eruption as well as the general accuracy of the respective input parameters:

a) During the later stages of an eruption, an increase of ME with a decrease of SE will likely be observed as ash concentrations will drop below the detection limit of the respective sensor while they are still present in the model run. This could potentially be exploited to measure the sensitivity of the sensor and to adjust VATD models to predict ash movement more accurately.

Table 1: Parameters chosen for Puff and the Volcanic Ash Retrieval $\left[^{*}\right.$ as described by Waythomas et al. (2010); NCAR=National Center for Atmospheric Research]

\begin{tabular}{cc}
\hline Puff & \\
\hline Start Time & $22: 00$ UTC \\
Start Date & August 7, 2008 \\
End Time & $05: 00$ UTC \\
End Date & August 8, 2008 \\
Number of Separate Events & $3^{*}$ \\
Vertical Particle Distribution & Poisson \\
Wind Model & NCAR \\
Number of Particles & 100,000 \\
& Based on \\
Eruption Rate & Sparks et al., \\
& 1997 \\
Particle Size Distribution & Based on \\
& Mastin et al., \\
Amount of Fines $(<63 \mu \mathrm{m})$ & $40 \%$ \\
\hline
\end{tabular}

b) In cloudy settings, RA images often show a high number of false alarms, especially with a threshold of $0 \mathrm{~K}$ [Prata, 1989]. When manually interpreting the results, it cannot be ruled out that there is ash beneath the meteorological clouds. An inclusion of the respective pixels in the RA data set can raise the SE value. High numbers of SE and ME values can therefore be indicative of cloudy scenes.

c) Similar shapes of SE and ME values on opposite ends of the ash cloud can indicate a shift of the ash, potentially due to an uncorrected parallax in the 
ANNALS OF GEOPHYSICS, XXI, 1, 2015

satellite data or to incorrect wind information in the model settings.

The ideal case is a CSI value of 1 . When this is not the case, both data sets need to be evaluated regarding the possible cause of this offset. The introduction of ME and SE values can prove valuable in addressing this problem.

\section{RESUltS}

An example of the Puff runs for the Kasatochi 2008 eruption can be seen in Figure 1A. The model output at 23:00 UTC on August 8, 2008, is colour-coded by height above sea level and disperses across the North Pacific Ocean to the east. The accompanying SE, CSI and ME values for each time step show the development of the ash cloud in reference to the model and observational data input. Figure $1 \mathrm{~B}$ represents the time-coinciding values of the ash dispersal depicted in Figure 1A.

The analysis shows a large ME area to the east of the cloud that coincides with the lower parts of the modelled ash cloud (approximately below $12 \mathrm{~km}$ above sea level) as shown in Figure
1A. The red area represents the SE value, which is relatively large and goes back to the volcano and further west where, to the best of our knowledge, some ash still existed. The CSI area is located between both Excess Values.

When comparing the different values over time (Figure 1C), an initial high percentage of $\mathrm{ME}$ is quickly lowered by noon of August 9 before it peaks at over $90 \%$ shortly before the end of our analysis (August 10, 23:00 UTC). The SE value, on the other hand, has its peak at the end of August 8, roughly coinciding with Figures $1 \mathrm{~A}$ and $\mathrm{B}$. By the end of the three day window, this value has reached $0 \%$. The CSI value increases at the beginning of the eruption up to $60 \%$ (August 9, 15:00 UTC) but decreases in the later stages to about $10 \%$.

The overall trend during the eruption shows more fluctuation during the first few hours, with SE values of 0 shortly after the onsets of new events, than during the end where comparably steady in- and decreases of the different values can be observed.
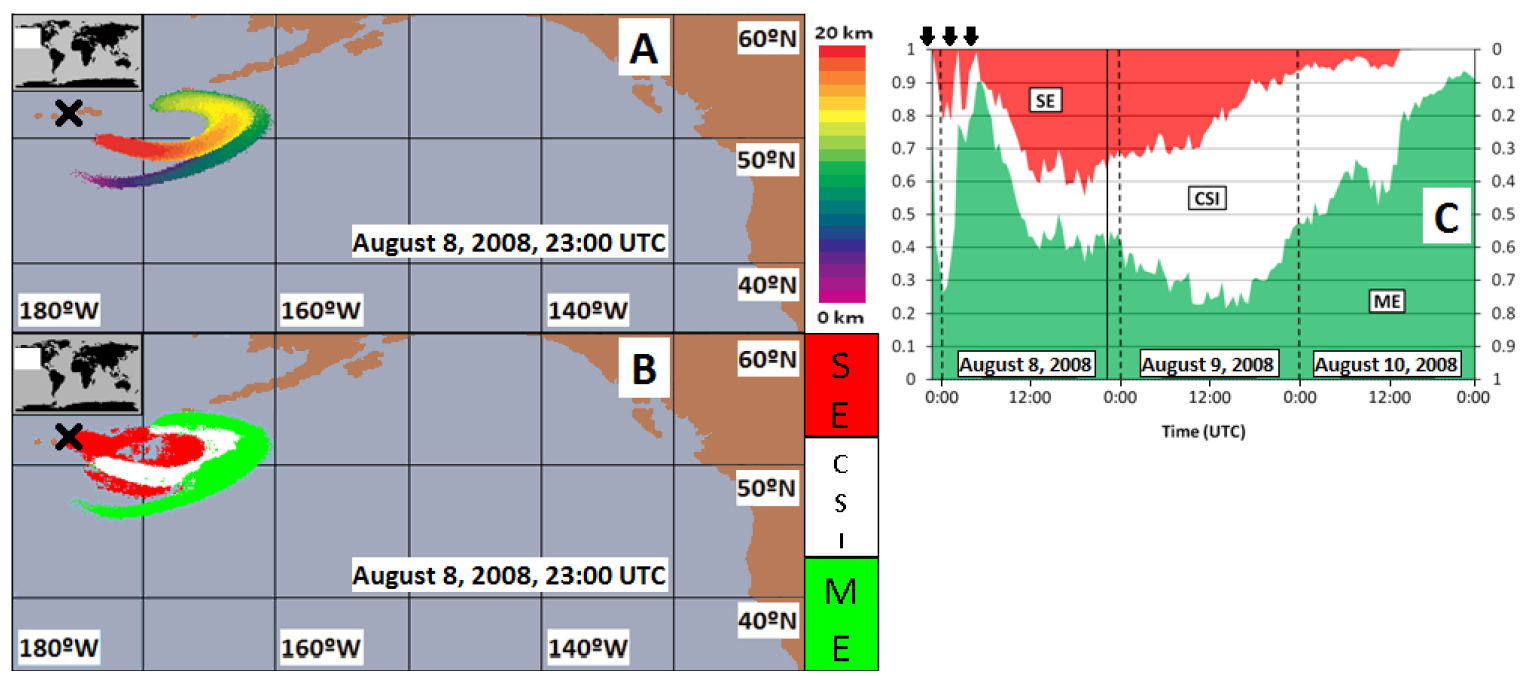

Figure 1: Location of the Kasatochi volcano in the Alaskan Aleutian Islands (black cross). (A) Snapshot from the results of the Puff run from the Kasatochi eruption in 2008. The color-coding is based on the ash height. (B) SE, CSI and ME values corresponding to the Puff scene in (A). Note that the ME values covers the lower part of the cloud, approximately up to $10 \mathrm{~km}$ above sea level.(C) Development of SE, CSI, and ME values over the course of the whole eruption. Towards the end, ME dominates and SE decreases to 0.The timing of $S$ and B is highlighted by the solid black line. Arrows indicate the onset of different events as described by Waythomas et al. (2010). 


\section{DisCUSSION}

The high SE values in the earlier parts of the eruption likely represent an overestimate based on satellite and auxiliary data. An example of this can be seen in Figure 1B where the expected ash extent goes back to the volcano while the model does not predict this.

Theoretically, this can also be caused by wrong model parameters but, due to the patchy character of the area, false alarms based on meteorological cloud cover are more likely.

Figure $1 \mathrm{C}$ also shows an SE value of 0 shortly after the onsets of each event. This is due to the ash breaching the meteorological cloud cover. It reaches heights where it can easily be identified in satellite data. However, the larger part of the ash cloud beneath the meteorological cloud cover was not detected in satellite data, causing high ME values. The fluctuations in the values at the beginning of the time series are due to a small plume where a few pixel differences can add up to large percentages.

High ME values at the end of the analyzed period stem from an expanding ash cloud in the model data which could not be identified in the observed data sets. Towards the end of the ash dispersion, the ash concentration is likely too low for satellites to determine it and auxiliary data sets for this time did not exist.

These findings suggest that an analysis of the SE, CSI and ME values can quantify the accuracy of the data sets and predict the ash movement. Problems can be caused by meteorological cloud cover, low ash concentrations and small ash extents. It is important to note that high SE or ME values do not point directly at incorrect input parameters of a specific method, but rather show a discrepancy between the compared techniques. This disagreement can then be analysed and corrected.

Using this qualitative analysis of the atmo- spheric ash extent, we not only incorporate additional data sets an automated approach cannot analyze, we're also taking a step back from a quantization of ash masses in the atmosphere. While it is important to work towards an accurate assessment of volcanic ash, a mass analysis with limited satellite bands and default input parameters for satellite and VATD model data can artificially alter the masses by up to $+/-50 \%$ [Steensen and Webley, 2012]. For these scenarios, an approach as described here is the best option to evaluate the ash dispersal and to predict the ash movement. Following up on this method, VAR can be applied to the CSI area instead of the whole model extent, where the ash might be underneath meteorological clouds causing false readings.

\section{REFERENCES}

[Casadeval, 1994] Casadeval, T. J. (1994). The 1989-1990 eruption of Redoubt Volcano, Alaska: impacts on aircraft operations, Journal of Volc. and Geoth. Research, 62, 301-316.

[Draxler and Hess, 1997] Draxler, R. R. and Hess G. D. (1997). Description of the HYSPLIT_4 Modeling System. NOAA Technical Memorandum ERL ARL-224.

[Gu et al., 2005] Gu, Y., Rose, W. I., Schneider, D. J., Bluth G. J. S. and Watson I. M. (2005). Advantageous GOES IR results for ash mapping at high latitudes: Cleveland eruptions 2001. Geoph. Res. Letters, 32, L02305.

[Mastin et al., 2009] Mastin, L. G., Guffanti, M. , Servranckx, R., Webley, P., Barsotti, S., Dean, K., Durant, A., Ewert, J. W. , Neri, A., Rose, W. I., Schneider, D., Siebert, L., Stunder, B., Swanson, G., Tupper, A., Volentik, A. and Waythomas C. F. (2009). A multidisciplinary effort to assign realistic source parameters to models of volcanic ash-cloud transport and dispersion during eruptions. J. of Volc. and Geoth. Res., 186, 10-21. 
ANNALS OF GEOPHYSICS, XXI, 1, 2015

[Pavolonis, 2010] Pavolonis, M. J. (2010). Advances in Extracting Cloud Composition Information from Spaceborne Infrared Radiances - A Robust Alternative to Brightness Temperatures. Part I: Theory. Journal of Appl. Met. and Clim., 49, 1992-1012.

[Prata, 1989] Prata, A. J. (1989). Observations of volcanic ash clouds in the 10-12 $\mu \mathrm{m}$ window using AVHRR/2 data. Int. J. Remote Sensing, 10, 751-761.

[Rose et al., 1995] Rose, W. I., Delene, D. J. , Schneider, D. J., Bluth, G. J. S., J. Krueger, A., Sprod, I., McKee, C., Davies, H. L. and Ernst, G. G. J. (1995). Ice in the 1994 Rabaul eruption cloud: implications for volcano hazard and atmospheric effects. Letters to Nature, 375, 477479.

[Ryall et al., 1998] Ryall, D. B. and Maryon, R. H. (1998). Validation of the UK Met Offices NAME Model Against the ETEX Dataset. Atm. Env., 32, 4265-4276.

[Sparks et al., 2007] Sparks, R. S. J., Bursik, M. I., Carey, S. N., Gilbert, J. S. , Glaze, L. S., Sigurdsson H. and Woods A. W. (2007). Volcanic Plumes. John Wiley \& Sons, Chichester.

[Steensen and Webley, 2012] Steensen, T. and Webley P. (2012). Qualitative Analysis of Input Parameters for Satellite-Based Quantification of Airborne Volcanic Ash. IEEE International: 2012, 2982-2985.

[Steensen et al., 2013] Steensen, T., Stuefer, M., Webley, P., Grell G. and Freitas S. (2013). Qualitative comparison of Mount Redoubt 2009 volcanic clouds using the PUFF and WRF-Chem dispersion models and satellite remote sensing data. J. of Volc. and Geoth. Res., Special Issue on the 2009 Redoubt Eruption, 259, 235-247.

[Stunder et al., 2007] Stunder, B. J. B., Hefter J. L., and Draxler, R. R. (2007). Airborne Volcanic Ash Forecast Area Reliability. Weather and Forecasting, 22, 1132-1139.

[Tanaka, 1991] Tanaka, H. L. (1991). Development of a Prediction Scheme for Volcanic Ash
Fall From Redoubt Volcano, Alaska. Volcanic Ash and Aviation Safety: USGS Bulletin: 2047, 283-291.

[Waythomas et al., 2010] Waythomas, C. F., Scott, W. E., Prejean, S. G., Schneider, D. J., Izbekov P. and Nye, C. J. (2010). The 7-8 August 2008 eruption of Kasatochi Volcano, central Aleutian Islands, Alaska. J. of Geoph. Res., 115, B00B06.

[Wen and Rose, 1994] Wen, S. and Rose, W. I. (1994). Retrieval of sizes and total masses of particles in volcanic clouds using AVHRR bands 4 and 5. J. of Geoph. Res., 99, 5421-5431. 